East African Medical Journal Vol. 77 No. 5 May 2000

FACTORS INFLUENCING COMPLIANCE IN PATIENTS WITH TUBERCULOSIS ON DIRECTLY OBSERVED THERAPY AT ILE-IFE, NIGERIA.

G.E. Erhabor, MBBS, FWACP, Senior Lecturer/Consultant Physician, Department of Medicine, H.S. Aghanwa, MBBS, FWACP, Lecturer/Consultant Psychiatrist,

Department of Mental Health, M. Yusuph, MBBS, Registrar, R.A. Adebayo, MBChB, Registrar, Department of Medicine, F.A. Arogundade, MBBS, Registrar, Department

of Medicine and A. Omidiora, MBChB, Registrar, Department of Medicine, Obafemi Awolowo University Teaching Hospitals Complex, Ile-Ife, Nigeria.

Request for reprints to: Dr. H.S. Aghanwa, Fiji School of Medicine, Brown Street, Suva, Fiji Islands, South Pacific Region.

\title{
FACTORS INFLUENCING COMPLIANCE IN PATIENTS WITH TUBERCULOSIS ON DIRECTLY OBSERVED THERAPY AT ILE-IFE, NIGERIA
}

\section{G.E. ERHABOR, H.S. AGHANWA, M. YUSUPH, R.A. ADEBAYO, F.A. AROGUNDADE and A. OMIDIORA}

\begin{abstract}
Background: Increased morbidity and mortality of tuberculosis have been blamed on neglect of the human dimension of tuberculosis control. One of such factors included in human dimension is non-compliance, a behavioural parameter, which has led to the emergence of multi-drug resistant tuberculosis, and poor treatment outcome.

Objective: To explore the impact of directly observed therapy (DOT) on compliance and the factors influencing it.

Design: A retrospective study.

Setting: Chest clinic of Obafemi Awolowo University Teaching Hospitals Complex, Ile-Ife, Nigeria.

Methods: Directly observed therapy (DOT) was employed. Records of the socio-demographic characteristics, treatment categories, complications developed, results of investigations, level of compliance and treatment outcome for the patients were kept. The data for the patients seen between May 1996 and April 1997 were retrieved and analysed. Those that complied were compared with those that did not comply.

Results: One hundred and ninety nine patients comprising ninety one males and 108 females, were seen during the period .They were mostly between the ages of 16 years and 45 years(mean \pm SD $=31.7 \pm 14.98)$. One hundred and fifty eight $(73 \%)$ complied and all of them were cured. The only factor that significantly influenced rate of compliance was proximity to the chest clinic.

Conclusion: DOT improves the rate of compliance. No socio-demographic factors considered significantly influenced the rate of compliance under DOT, and as such they are not reliable predictive factors. Locating chest units in the existing primary health care facilities will improve the rate of compliance with antituberculosis therapy. More attention should be paid to behavioural aspect of tuberculosis control.
\end{abstract}

\section{INTRODUCTION}

Morbidity and mortality from tuberculosis have been on the increase in spite of increased understanding of its natural history and major advances in the technology involved in its management within the past 50 years. Indeed, Mycobacterium tuberculosis remains the world leading cause of death from a single infectious agent $(1,2)$. Every year, about eight million people develop this disease and some three million die of it, over $95 \%$ of these from developing countries including Nigeria $(1,3,4)$. It is noteworthy that most of the deaths from developing countries occur in persons aged between 15 and 59 years, thereby making tuberculosis a leading cause of death within the economically productive groups of the population $(5,6)$. Among the countries of high-burden are India, Indonesia, Pakistan, Bangladesh, China and Nigeria, and progress in these high-incidence countries has been described as the key to global tuberculosis control(7).
Recently, there has been a resurgence in its prevalence in Europe and North America where active control programmes have existed for decades. This is partly due to the cruel duet of human immunodeficiency virus (HIV) infection and tuberculosis, and the emergence of multidrug resistant tuberculosis. Tuberculosis, therefore, constitutes a major public health problem for all age groups in both economically backward countries and technologically advanced nations.

The World Health Organisation's (WHO) goal of tuberculosis control, which aims at reducing the annual death rate by $40 \%$ from its present level of 2.9 million to 1.7 million, seems elusive(1). This failure has been blamed on numerous factors among which are inadequate emphasis on the human dimension of tuberculosis control $(3,8,9)$. Non-compliance, a behaviour parameter, remains a major cause of poor utilisation of available facilities resulting in multi-drug resistance and therapeutic failure $(10,11)$. 
Different methods have been developed to promote adherence to antituberculosis drugs. These include: inbuilt monitoring system(1), pill counts, combination tablets, blister packs, urine tests, hospitalisation and supervised therapy $(8,12)$. Recently, directly observed therapy (DOT) was introduced to a number of chest clinics to promote compliance. This method entails an outreach worker/ nurse delivering antituberculosis drugs to the patient and observing the patient ingesting his drugs. This paper is aimed at evaluating the effectiveness of DOT in improving patients' adherence to treatment among Nigerian tuberculosis population, and to examine the sociodemographic factors that might influence it.

\section{MATERIALS AND METHOD}

This study was conducted in the chest clinic of Obafemi Awolowo University Teaching Hospitals Complex (OAUTHC) Ile-Ife. Ile-Ife is a university town and it is located in the southwest about $229 \mathrm{~km}$ from Lagos, the major commercial centre of Nigeria. The staff of the clinic includes a consultant chest physician, a number of resident doctors in respiratory medicine, nurses and other ancillary staff.

Suspected cases of pulmonary tuberculosis are referred to the chest clinic from the general out-patient departments and other consultant clinics in the hospital. Referrals are also obtained from other health care facilities in the surrounding states. The tuberculosis clinic is run twice every week. An average of five to eight new cases are seen per week, and follow up cases of 25-50 patients per month.

At the clinic, patients are seen by the attending physician who makes the diagnosis and commences treatment. To be included in Directly Observed Therapy (DOT), the patient must fulfil the following criteria: (i) must have two random sputum and an early morning sputum examination of which at least two must be positive for tuberculosis and; (ii) in addition, although not an absolute criterion, the patient must have a chest $\mathrm{x}$-ray, showing evidence of pulmonary tuberculosis.

Patients on DOT are allocated to one of the three categories of treatment(13) (Table 1). The patient is encouraged to go to the nurses with a cup of water, and takes the anti-tuberculosis medication in the presence of the clinic staff. The treatment is supported by the Damien Foundation, and all patients are treated free of charge.

Since the inception of DOT in May 1996 records of the patients' socio-demographic parameters, clinical status, results of investigations, degrees of compliance, categories of treatment, complications developed and treatment outcome have been kept. This study covered those patients on DOT in this centre between May 1996 and April 1997. The patients were grouped into two categories: compliant and non-compliant groups. To be categorised into compliant group the patient must have fulfilled the following criteria: (i) must have taken his or her drugs conscientiously for the period specified under his or her category of treatment, (ii) must have completed all the laboratory investigations required and; (iii) the patient's compliance must have been certified by the resident physician and the administrative nurse by careful study of the attendance and treatment record.

Table 1

Categories of treatment

\begin{tabular}{|c|c|c|}
\hline Category & $\begin{array}{l}\text { Type of } \\
\text { tuberculosis } \\
\text { patients }\end{array}$ & $\begin{array}{l}\text { Types of } \\
\text { antituberculosis } \\
\text { regimen }\end{array}$ \\
\hline Category 1 (Duration: six months) & $\begin{array}{l}\text { (a) New sputum } \\
\text { smear positive } \\
\text { pulmonary } \\
\text { tuberculosis. } \\
\text { (b) Newly diagnosed } \\
\text { seriously ill-patient. } \\
\text { (c) Severe form of } \\
\text { pulmonary tuberculosis }\end{array}$ & $\begin{array}{l}\text { Initial intensive phase } \\
\text { Daily for two months; } \\
\text { isoniazid, rifampicin and } \\
\text { either streptomycin or } \\
\text { ethambutol. } \\
\text { Continuation phase } \\
\text { Daily for six months: } \\
\text { isoniazid, thiacetazone }\end{array}$ \\
\hline Category 2 (Duration: eight months) & $\begin{array}{l}\text { (a) Relapsed cases } \\
\text { (b) Treatment failure } \\
\text { (c) Return after default } \\
\text { (d) Sputum smear positive }\end{array}$ & $\begin{array}{l}\text { Initial intensive phase } \\
\text { Daily first, second and third } \\
\text { months; isoniazid, } \\
\text { rifampicin, pyraziamide. } \\
\text { Continuation phase } \\
\text { Thrice weekly for five } \\
\text { months isoniazid+ } \\
\text { rifampicin or isoniazid + ethambutol }\end{array}$ \\
\hline Category 3 (Duration: 12 months) & $\begin{array}{l}\text { (a) Sputum smear } \\
\text { negative pulmonary } \\
\text { tuberculosis with limited } \\
\text { parenchymal } \\
\text { involvement. } \\
\text { (b) Extrapulmonary } \\
\text { tuberculosis( less severe } \\
\text { form ) }\end{array}$ & $\begin{array}{l}\text { Initial intensive phase } \\
\text { Daily for two months: } \\
\text { streptomycin, isoniazid+ } \\
\text { thiacetazone(combined) } \\
\text { Continuation phase } \\
\text { Daily for } 10 \text { months: } \\
\text { isoniazid+ } \\
\text { thiacetazone(combined) }\end{array}$ \\
\hline
\end{tabular}


In this study the patients' occupations were classified according to the International Classification of Occupations(14).

Analysis of data: The compliant and non-compliant groups were compared using simple frequency and Chi-square test. Critical level of statistical significance was set at 0.05 and statistical test was one-tailed.

\section{RESULTS}

One hundred and ninety nine patients were seen during the period under review. This comprised 91 males and 108 females. Their age range was seven to 80 years (mean $\pm \mathrm{SD}=31.7 \pm 14.98$ ). One hundred and fifty eight patients (73\%), completed their treatment while 41 (27\%) defaulted at some points. A majority (78.9\%) of the patients were between 16 and 45 years. Table 2 shows relationship between socio-demographic parameters and compliance.

Age: The mean age (s.d.) for the compliant group was $31.99 \pm 15.39$, while that of the non-compliant group was $31.50 \pm 14.95$. When the age groups were collapsed into two major groups $; \leq 45$ years and $>45$ years, and compared regarding compliance, the difference was not statistically significant $(\mathrm{p}>0.05)$.

Gender: Comparing the gender of the compliant and non-compliant groups, the difference was not significant $(\mathrm{p}>0.05)$.

Occupation: When the occupational groups were collapsed into two main groups: white collar jobs and others, and compared with regards to compliance, the difference was not statistically significant ( $p>0.05$ )

Religion: No significant difference was found when the religion of the two groups was compared ( $p>0.05)$.

Distance to the hospital: Considering the relationship between the distance of the patient's residence to the Chest Clinic and the rate of compliance, it was found that a higher proportion of those in the compliant group (as against those is the non-compliant group) lived within $25 \mathrm{~km}$ to the clinic. The difference was statistically significant $(\mathrm{p}<0.05)$. Table 3 illustrates the relationship between treatment categories/ complications and rate of compliance.

Table 2

Relationship between socio-demographic characteristics and rate of compliance

\begin{tabular}{|c|c|c|c|}
\hline Parameter & $\begin{array}{l}\text { Compliant group } \\
(\mathrm{n}=158)\end{array}$ & $\begin{array}{l}\text { Non-compliant group } \\
(\mathrm{n}=41)\end{array}$ & Statistical analysis \\
\hline \multicolumn{4}{|l|}{ Age (years) } \\
\hline$<15(n-9)$ & $8(5.0 \%)$ & $1(2.4 \%)$ & (collapsed into two groups) \\
\hline $16-25(n=26)$ & $58(36.7 \%)$ & $18(43.9 \%)$ & \\
\hline $26-35(n=56)$ & $45(28.5 \%)$ & $11(26.8 \%)$ & $\chi 2=0.14$ \\
\hline $36-45(n=25)$ & $20(12.7 \%)$ & $5(12.2 \%)$ & $\mathrm{df}=1$ \\
\hline $46-55(n=14)$ & $12(7.6 \%)$ & $2(4.9 \%)$ & $\mathrm{p}>0.05$ \\
\hline $56-65(\mathrm{n}=12)$ & $10(6.3 \%)$ & $2(4.9 \%)$ & \\
\hline$>65(\mathrm{n}=7)$ & $5(3.2 \%)$ & $2(4.9 \%)$ & \\
\hline \multicolumn{4}{|l|}{ Gender } \\
\hline Male $(n=91)$ & $72(45.6 \%)$ & $19(46.3 \%)$ & $\chi 2=0.644, \mathrm{df}=1$ \\
\hline Female $(n=108)$ & $86(54.4 \%)$ & $22(53.7 \%)$ & $\mathrm{p}>0.05$ \\
\hline \multicolumn{4}{|l|}{ Occupation* } \\
\hline Groups $0+1$ & $10(6.3 \%)$ & $4(9.7 \%)$ & $\chi 2=0.0309$ \\
\hline (Profes. + Admin) & $49(31.0 \%)$ & $12(29.3 \%)$ & $\mathrm{df}=1$ \\
\hline $2+3$ (Clerical + salesman $)$ & & & $\mathrm{p}>0.05$ \\
\hline $4,5,6,7,8$ and 9 & $52(32.9 \%$ & $15(36.6 \%)$ & \\
\hline \multicolumn{4}{|c|}{ (Farmers, artisans, service workers) } \\
\hline \multicolumn{4}{|c|}{ (Unemployed, students, unidentified job) } \\
\hline \multicolumn{4}{|c|}{ Religion } \\
\hline Christianity $(n=142)$ & $113(71.5 \%)$ & $29(70.7 \%)$ & $\begin{array}{l}\chi 2=0.3449 \\
\mathrm{df}=2\end{array}$ \\
\hline Islam $(n=44)$ & $34(21.5 \%)$ & $10(24.4 \%)$ & $p>0.05$ \\
\hline Religion not indicated $(n=13)$ & $11(7.0 \%)$ & $2(4.9 \%)$ & \\
\hline Distance to hospital ${ }^{* *}(\mathrm{~km})$ & $143(91.1)$ & $29(70.7)$ & $\chi 2=13.92, \mathrm{df}=1$ \\
\hline$\leq 25 \mathrm{~km}(\mathrm{n}=172)$ & $14(8.9)$ & $12(79.3)$ & $\mathrm{p}<0.05$ \\
\hline$>25 \mathrm{~km}(\mathrm{n}=26)$ & & & \\
\hline
\end{tabular}

* The occupational groups were collapsed into two categories: white collar and non white collar jobs.

** Distance not indicated in one case that complied and excluded in the analysis. 
Table 3

Relationship between treatment category/complication and rate of compliance

\begin{tabular}{|c|c|c|c|}
\hline & Compliant group & Non-compliant group & Statistical analysis \\
\hline \multicolumn{4}{|l|}{ Treatment category } \\
\hline $\begin{array}{l}\text { Category } 1 \\
(n=163)\end{array}$ & $130(79.8 \%)$ & $33(2 \%)$ & $\chi 2=1.944$ \\
\hline $\begin{array}{l}\text { Category } 2 \\
(\mathrm{n}=2)^{* *} \\
\text { Category } 3(\mathrm{n}=34)\end{array}$ & $\begin{array}{l}2(100.0 \%) \\
26(76.5 \%)\end{array}$ & $\begin{array}{l}0(0 \%) \\
8(5 \%)\end{array}$ & $\begin{array}{l}\mathrm{df}=1 \\
\mathrm{p}>0.05\end{array}$ \\
\hline $\begin{array}{l}\text { Complications } \\
\text { Pulmonary } \mathrm{Tb}\end{array}$ & & & \\
\hline $\begin{array}{l}\text { with complications }(n=45) \\
\text { Pulmonary } T b \text { without }\end{array}$ & $36(80.0 \%)$ & $9(20.0 \%)$ & $\chi 2=0.314$ \\
\hline complications $(n=154)$ & $122(79.2 \%)$ & $32(20.8 \%)$ & $\begin{array}{l}\mathrm{df}=1 \\
\mathrm{p}>0.05\end{array}$ \\
\hline
\end{tabular}

**Category 2 was not included in the analysis because of small sample size.

The category of treatment did not significantly influence the rate of compliance of the patients ( $p>0.05)$. The presence of complications did not significantly influence the rate of compliance with antituberculosis treatment ( $p>0.05)$. All the patients who completed their treatment in all categories were cured of tuberculosis as evident by a satisfactory clinical state and sputum smear negativity.

\section{DISCUSSION}

Non-compliance is cited as a major obstacle to the control of tuberculosis at the level of public health $(15,16)$. It is also a serious problem in the treatment of individual patients and in the development of drug resistant strains. Therefore the introduction of directly observed therapy has been welcomed worldwide as an effective method to stop this trend. Prior to the commencement of DOT in our centre, the rate of compliance with tuberculosis therapy was reported to be as low as $20 \%$ (Jeje, A.M., personal communication). This is similar to the rates of $\leq 50 \%$ found in similar African settings where directly observed therapy has not been commenced(1). However, in the present study, the rate of compliance with antituberculosis regimen under directly observed therapy was found to be high (73\%). A similar improvement in the rate of compliance was reported from South Africa when voluntary health workers were employed to supervise therapy(8). The increase in rate observed in the present study may be due to the following advantages derived from DOT: regular supervision of the patients' drug administration, supply of antituberculosis drugs free of charge, provision of opportunities for educating the patient by the clinic staff on the natural history of the disease and the control strategies, and short term chemotherapy involved.

Our figure was however lower than that of Farmer et al(17), who reported a compliance of $100 \%$ from rural Haiti, and those of Westaway(18) in South Africa (91\%) and Manalo et al(19) in Manila (90\%). These studies differ from ours in that the programmes were more comprehensive. Incentives such as nutritional assistance, travel expenses to attend clinics, and home visit when patients failed to attend clinics were included. Many patients with tuberculosis suffer from a wide range of social problems, which include: homelessness, poverty and psychological disorders. A successful programme must take into consideration these difficulties and appropriate incentives should be included as part of a comprehensive programme. Local factors should be considered in detail in formulating the content of the incentives that would be applicable.

Among the socio-demographic/geographical factors, which influence compliance in the present study, it was only with the distance of the patient's residence to the chest clinic that a significant effect was observed. Proximity to the chest clinic has a direct relationship with the rate of compliance. This is expected in a developing country where cost of transportation constitutes a significant proportion of the overall treatment cost, and in an environment where it was earlier reported that the majority of people were willing to travel only five miles $(8 \mathrm{~km})$ to seek health care(20). Fortunately, the majority of our patients live within $25 \mathrm{~km}$ to the hospital. It can therefore be suggested that chest units be set up in the existing primary health care facilities to enhance greater patientcoverage. Support and fund from external sources can therefore be channelled to these smaller units by the tertiary centre, which will undertake supervisory role as well as function as a referral centre for difficult cases.

It was observed that a higher proportion of children complied, while marginally lower proportions of economically productive groups in the population and elderly people complied; although the difference was not statistically significant. The reason for this finding is not clear. Perhaps it is due to the fact that economically active people engage in a wide variety of occupational activities in order to sustain the entire family in this depressed economy, and therefore have less time to attend clinics regularly. The relatively lower proportion of elderly patients in the compliant group is similar to the observation made in East Africa(21). This may be attributed to poor financial resources(22) arising from reduced productivity and high rate of attrition associated with ageing. 
In this study, types of occupation seemed to have no effect on the rate of compliance. This is contrary to the expectation that being in a white collar job would be an advantage. Indeed, in similar studies conducted in South Africa and Vietnam, it was found that both staff and patients of Chest Clinics believed that tuberculosis was a stigma and 'dirty' disease. Consequently, some of the patients in those countries avoided seeking help from chest clinics $(23,24)$. Also in earlier studies, it was found that general education and knowledge of tuberculosis was not an advantage with regards to early presentation to and compliance with appropriate medical services(8). Older age, female gender and higher level of education have been associated with better adherence in some studies, but no associations have been found in others(12). It appears that socio-demographic variables are unreliable or inconsistent in predicting adherence.

The effect of complications on the rate of compliance was also examined. The same proportion of patients with complications complied with treatment as those that did not have complications. The nature of the complications had no influence on the rate of compliance too. Perhaps the diagnosis of tuberculosis is perceived with enough seriousness to warrant good compliance with treatment, under directly observed therapy, whether or not the patient develops complications.

This study confirms that DOT improves rates of compliance. Non-compliance, a behavioural factor, has been implicated as a major cause of failure of tuberculosis control. The presence of psychopathology has been found to be one of the causes of non-compliance with therapy in chest conditions $(25,26)$. In an earlier study on a tuberculosis population in the same setting, it was found that $30.2 \%$ of the population had diagnosable mental disorders and none of these were recognised by the clinic staff(27). It is therefore possible that psychopathology could have adversely affected the rate of compliance in the present study; although this factor requires further elucidation in a future study. In order to maximise the rate of compliance, health workers involved in the management of these patients should develop a higher index of suspicion for possible psychopathology and utilise the available consultation/liaison psychiatric services;

The cause of non-adherence to treatment in this population appears to be multifactorial. The factors include psychopathology, poor economy, geographical disadvantages, inadequate knowledge about treatment strategies and non-challant attitude associated with denial of the presence of an illness. The degree to which each of these factors contributes will probably be the subject of another study.

It is believed that as more attention is paid to the human dimension of tuberculosis, its global control will be achieved. This human dimension includes: the patient's psychological attitude towards the disease and its treatment, the health professionals' attitude and behaviour towards the patient, and the governments' motivation for and commitment towards tuberculosis research and control. It is hoped that this study will stimulate further work in this previously neglected but vital aspect of disease control, especially in sub-Saharan Africa, where the incidence of tuberculosis is still on the increase.

\section{ACKNOWLEDGEMENTS}

To the members of staff of the chest clinic Obafemi Awolowo University Teaching Hospitals Complex (OAUTHC), Ile-Ife, Nigeria for making this study possible; to Professor O. Morakinyo, Head of Department of Mental Health Obafemi Awolowo University, Ile-Ife, Nigeria, for his useful contributions.

\section{REFERENCES}

1. Kochi, A. The global tuberculosis situation and the new control strategy of the World Health Organization. Tubercle 1991; 72: 1-6.

2. Martin, P. Tuberculosis at the end of the century. Med. Digest 1996; 22: 1014.

3. Benatar, R. Prospects for global health: lesson from tuberculosis. Thorax 1995; 50: 487-489.

4. Brown, P. A disease that is alive and kicking. Wld. Hlth. 1993; 4: 4-5.

5. Porter, J., McAdam, K., Feachem, R. The challenge is Intemational. Wld. Hlth. 1993; 4: 10-12

6. Murray, G.D.L., Styblo, K., Rovillon, A. Tuberculosis in developing countries: burden, intervention and cost. Bull International Union Against Tuberculosis and Lung Diseases (IUATLD) 1990; 65: 6-24.

7. Global Tuberculosis Control. WHO Report 1998 Global Tuberculosis Programme, World Health Organization Geneva.

8. Grange, M.J., Festenstein, F. The human dimension of tuberculosis control. Tuber. Lung Dis. 1993, 74: 219-222.

9. Smith, I. Tuberculosis Control: Learning Games. Trop. Doct. 1993; 23: 101-103.

10. Liefooghe, R., Michiels, N., Habib, S., Moran, M.B., De Muynets, A Perception and social consequence of tuberculosis: A focus group study of tuberculosis patients in Sialkot, Pakistan.Soc. Sci. Med. 1995; 41:1685-1692.

11. Tripathy, S.P. Multidrug - resistant tuberculosis. Wld. Hlth. 1993; 4: 19.

12. Surmatojo, E. When Tuberculosis treatment fails: A social behavioural account of patient adherence.Amer. Rev. Respir. Dis. 1993;147: 1311- 1320.

13. Enarson, D.A., Reider, H.L., Arnodottir, T. (ed): Tuberculosis guide for low income countries, 3rd edn, International Union Against Tuberculosis and Lung Disease, Paris, 1994

14. International Classification of Occupations (Extracted from "Application of International Standards to Census Data on the Economically Active Population". United Nations Population Studies No. 9, New York. 1951)

15. Addington, W.W. Patient compliance: the most serious remaining problem in the control of tuberculosis in the United States. Chest 1979; 76: 741743.

16. Fox, W. Self-administration of medicaments: a review of published work and a study of the problems. Bull. Int. Union. Tuberc. 1962; 32: 301-331.

17. Farmer, P. Robin, S. Ramilus, S.L., Kim, J.Y. Tuberculosis, Poverty, and "compliance": lessons from rural Haiti.Samin. Respir. Infect. 1991; 6: 254-260.

18. Westaway MS: Compliance with tuberculosis treatment, the role of the voluntary health worker. Report of the tuberculosis Research Institute of the Medical Research Council Pretoria, Republic of South Africa, 1988.

19. Manalo F, Tam F, Sbarbaro J.A., Iseman M.D. Community based short course treatment of pulmonary tuberculosis in a developing nation. Am. Rev. Respir. Dis. 1990, 142: 1301- 1305.

20. Adejuyigbe, O. Providing Health Centre in the Rural Areas of the Western State of Nigeria. Niger Med. J. 1974; 4: 6-12.

21. Demisssie, M. and Kebede, D. Defaulting from tuberculosis treatment at the Addis Ababa Tuberculosis Centre and factors associated with it . Ethiop. Med. J. 1994 ; 32: 97- 106

22. Westaway, M.S., Wolmarans, L. Cognitive and affective reaction of black urban South Africans towards tuberculosis. Tuberc. Lung. Dis. 1994; 75: 447-453.

23. Johanson, E., Piwan, V.K., Huong, N.D., Ahlberg, B.M. Staff and patient attitudes to tuberculosis and compliance with treatment. Tuber. Lung Dis. 1996; 77: 178-183.

24. Dick, J., Schoeman, J.H. Tuberculosis in the community: The perceptions of members of a tuberculosis health team towards a voluntary health worker programme. Tuberc. Lung Dis. 1996; 77: 380-383.

25. Bosley, C.M., Corden, Z.M., Rees, P. J., Cochrane, G.M. Psychological factors associated with use of home nebulized therapy. Eur. Respir. J. 1996; 9: 2346-2350.

26. Kolbe, J.. Asthma education, action plans, psychosocial issues and adherence. Can. Respir. J. 1996; 6: 273-280.

27. Aghanwa, H.S., Erhabor, G.E. Demographic/socio-economic factors in mental disorders associated with Tuberculosis in South West Nigeria. $J$. Psychosom. Res. 1998; 45: 353-360. 